\title{
The world's factory and informal ties - organisation of firm networks in the electronics industry in the Greater Pearl River Delta, China
}

\begin{abstract}
Institutional transition in countries such as China is expected to go hand in hand with the formalisation of interactional behaviour in firm networks. Recently, however, a different string of arguments has entered the academic discussion emphasising the limited extent of the formalisation of firms' behaviour despite the institutional transition being complete. The aim of this paper is to show conceptually and empirically that a balance of formal and informal interactions is considered optimal for firms due to economic opportunities resulting from informality. The Greater Pearl River Delta (PRD), where Hong Kong (HK) firms act as cross-border intermediates between global customers and Chinese producers, serves as an example for studying the degree of informality applied when operating in two distinct institutional settings. A survey of electronics firms in HK investigates the way in which firms organise their contacting and selecting as well as their contracting processes when approaching global customers and Chinese producers. The findings show (1) that the degree of informality is greater when interacting with producers in the PRD due to the incompleteness of the institutional setting, but (2) that when acting with global customers, the behaviour of firms is only formalised to a certain extent. Informal interaction also serves as an opportunity for firms and is strategically used in an innovative organisational and management processes.
\end{abstract}

Keywords: informality, institutions, business organisation, electronics industry, Hong Kong, China

\section{Introduction}

The Greater Pearl River Delta is responsible to a large extent for the economic growth and prosperity of China. It has made itself irreplaceable in the global value chain as a supplier for electronics products. The electronic firms in the region account for $38 \%$ of Chinese exports and $32 \%$ of the gross industrial output (Guangdong Provincial Bureau of Statistics 2007). The region is unique in contrast to Shanghai or Bejing due to the intense firm networks between Hong Kong (HK), an established hub for trade with formal institutions meeting international standards, and the Pearl River Delta Economic Zone (PRD), part of the Chinese province of Guangdong and the 'world's factory' in the middle of a transitional process. HK firms act as intermediaries between producers of electronic products in the PRD and the global customer base located in industrialised economies. HK firms manage to interact well with partners in two distinct institutional settings.

Following the general discussion, HK firms are expected to apply informal, more personal modes of interactions with PRD producers to overcome the institutional weaknesses in the $\mathrm{PRD}$, for example missing laws or an inadequate enforcement of existing laws. Informality in interactions is considered to be a necessity. Global customers, in contrast, are expected to be served in a more formal way. However, there are theoretical considerations which emphasise the advantage of informal interactions even though a complete institutional setting is in place, for example social safeguards, trusted advice, room for flexible actions. Therefore, this paper addresses a slightly different line of thought which considers informality in interaction as an opportunity for HK firms as well, rather than merely as a necessity. This paper aims (1) to contribute to the academic discus- 
sion on informal interactions in firm networks by adding a new strand of argumentation which turns away from informality as a necessity (survival strategy in transitional economies), towards informality as an opportunity to respond flexibly to the changing economic environment, (2) to open ways to operationalise and measure informal interactions and (3) to present initial empirical evidence to confirm that HK firms use informal interactions independently from the institutional setting.

A firm survey conducted in $\mathrm{HK}$ revealed to what extent informal interactions are applied in the contacting and selection of new partners and the design of contracts. The answers of HK firms pertaining to PRD producers and global customers were compared. It could be found that HK firms also apply informal modes of interaction with their global customer base despite the fact that formal institutions are perfectly developed. It seems to be a good alternative in combination with formal modes of interaction. It suits the need for speed in the negotiation processes resulting from volatile market conditions and provides the flexibility required to change agreements. Considering informal interactions as a conscious and strategic method in business organisation, it can be viewed as a managerial innovation. Understanding business concepts in Asia may produce learning effects.

In the first section, this paper sheds light on the two lines of argument from a conceptual point of view: informality as a necessity versus informality as an opportunity. In the second part the focus is turned to the operationalisation of informal interactions and methods with which to measure it. The third section presents an empirical study of whether informal behaviour disappears with the development of comprehensive formal institutions on a regional level, or whether informal arrangements are considered as an opportunity for doing business independently of the institutional setting.

\section{Smoothing business relations: new perspectives on informality}

The recent academic discussion on informal interactions in business relations has moved away from non-legalisation and informal economies towards the importance of informal institutions and, beyond that, even towards infor- mal behaviour. In order to explain informal modes of interaction between economic agents, there are two arguments on which to focus. On the one hand, informal interactions may be a consequence of inefficient formal institutions. Informal interactions are considered to be a necessity (WILLIAMSON 2000). On the other hand, informal arrangements and behaviour may simply be perceived by firms as more efficient, although these firms may act within a complete institutional setting. Informal interaction is viewed as an opportunity (ETZOLD et al. 2009; LI 2007; SINDZINGRE 2006). The study of whether informality in business interactions is driven by necessity or opportunity requires a particular investigation of a region's institutional environment and its evolution. These factors shape the framework conditions for firms' interactional behaviour.

\section{Informal interactions as a necessity: inefficient formal institutions}

Formal and informal institutions influence the behaviour of firms. Informal constraints are characterised by the customs, norms, traditions, culture and religion of a region. They are based on implicit understanding and are socially derived, which makes them inaccessible through written documents. Informal institutions are path-dependent and have a long, pervasive influence on the character of economic development. They are also roots for the development of formal rules. The two are interwoven (WiLliamson 2000, 595 ff.). Formal rules involve laws and regulations (RICHTER/ FURUBOTN 1996, 3 ff.). Although there is a clear distinction between formal and informal institutions (rules) and formal and informal behaviour of firms (actions), it can generally be agreed that formal institutions shape the path for formal behaviour (e.g. a comprehensive contract law encourages formal contracts) and informal institutions guide informal behaviour (e.g. a culture of harmony avoids formal disputes between partners), even though exceptions exist.

This picture loses its simplicity when turning to economies under institutional change, such as China. There are two arguments as to why firms perceive a deviation from formal interactions as necessary. Firstly, formal institutions are not completely in place following the arguments of the New Institutional Economics. In their absence, firms are expected to rely on existing informal institutions. Secondly, prob- 
lems occur because of a disharmony between formal and informal institutions. In transitional economies, formal institutions are mainly transferred from Western economies and are slightly adapted to local needs. This is, in general, more cost-efficient and time-saving than developing a new system. However, formal institutions are not rooted in regionally specific informal institutions (WILLIAMSON 2000). It is essential for successful reforms to change both the formal institutions and the belief systems (NORTH 1990). Otherwise, firms, led by individuals, will not support the new economic rules of the game, since their method of doing business is shaped by informal institutions and is not compatible with the new rules (GRANOVETTER 1973). It is not only the existence of formal institutions, but rather the costs, the efficiency and the willingness to use them which makes them attractive for firms. This explains why the economic system in some nations still does not work effectively, even though formal institutions are well developed.

Although laws in China have been reformed, their functionality is still limited. At the same time, the Chinese are equipped with a set of strong informal institutions guiding social and economic interactions - guanxi. Basically, guanxi describes a personal connection between two people or a network of contacts, the idea of which is to draw on established connections in order to secure favours in personal interests (DUNNING/KIM 2007, LUO/CHEN 1997, PARK/LUO 2001). These informal rules are already in place and may act perfectly as substitutes for dysfunctional and costly formal rules. The traits of guanxi are manifold (Tab. 1). Firstly, guanxi operates on the level of individuals and corresponds to a highly personal relationship. Secondly, guanxi is reciprocal in the exchange of favours. Reciprocal processes are seen as a supplement to formal procedural rules. They involve mutual expectations on the part of the economic agents that a favour granted now will be repaid later. It is perpetual. Reciprocity can also result in mutual dependency. Thirdly, guanxi is an intangible asset. People in the network are committed to each other through an informal and unwritten code of trust. This guards against opportunistic behaviour, as the reputations of individuals are damaged when they disappoint their partners. Fourthly, guanxi is long-term oriented. Every guanxi relationship expands the stock of relational capital. It takes time to establish a functional guanxi network. Investments are initially high, but if a guanxi network is established, it enables firms to react quickly to changes and provides them with a certain degree of flexibility. Fifthly, guanxi is transferable. If $\mathrm{A}$ has guanxi with $\mathrm{B}$, and $\mathrm{B}$ is a friend of $\mathrm{C}$, then $\mathrm{B}$ can introduce and recommend A to C. Finally, guanxi is a utility concept. It is based on the exchange of favours, not on sentiments. If guanxi with other parties is no longer achieving objectives, it is easily broken (DUNNING/KIM 2007, 330 f.; LUO/CHEN 1997; PARK/LUO 2001, 457).

A manager's guanxi network is part of the Chinese way of doing business. Guanxi relations as found in Chinese society cannot easily be created - they are socially derived and are regionally embedded. Most of the contacts are built with people in spatial proximity, as trust and frequent interaction are the fundamental axes of guanxi. The network of guanxi is connected to a certain region, although guanxi also has the potential for long-distance relations, for example when family members or classmates move. The strong definition of informal rules supports entrepreneurs in adequately safeguarding their transactions in the absence of economic laws. For example, firms are hard-

Tab. 1: The traits of guanxi

\begin{tabular}{ll} 
Traits & Description \\
\hline Personal & Guanxi is established between individuals \\
Reciprocal & An individual's reputation is tied up with reciprocal obligation \\
Intangible & Guanxi maintained by an unspoken commitment \\
Long-term & Guanxi is reinforced through long-term cultivation \\
Transferable & Guanxi is transferable through a third party as a referral \\
Utilitarian & Guanxi is purposefully driven by personal interests \\
\hline
\end{tabular}

Source: according to DunNING/KIM 2007, 331 
ly able to enforce contracts in the case of conflicts due to a lack of functionality of the Chinese court system.

Despite all the positive effects of guanxi, it can also lead to lock-in effects, for example when firms are forced to select customers and producers via social ties (e.g. family members) instead of choosing the highest quality partner on a market basis. In other cases, firms cannot enforce contracts without considering the fact that this could burden the relationship. Therefore, it may be expected that against the background of profit maximisation, the guanxi network might become more functionally driven by personal connections and profit orientation. Business connections would then be associated with moderate informality, whereas private contacts are associated with a high degree of informality.

According to the New Institutional Economics, institutional change in transitional economies setting up a complete set of formal institutions in harmony with existing informal rules - is expected to lead to a gradual formalisation of interactions. However, this paper goes beyond that and follows the idea that a sophisticated set of informal interactions could still work efficiently in business operations even though formal institutions are modernised. There might be a trade-off point where formal interactions substitute for informal behaviour of firms, indicating optimal behaviour. Following these lines of thought, this paper addresses YEUNG/LIN's (2003) call for a context-specific theorising of the economic geographies of Asia.

\section{Informal interactions as opportunity - benefiting by smoothing business relations} If interactions are formalised only to some extent in the course of institutional transition and keep a certain level of informality due to more efficient outcomes, informal interactions in business are no longer transitional, but become permanent. This line of argumentation states that there is not necessarily a complete formalisation of interaction, even if sufficient safeguards are provided by the current law system. Formal and informal interactions no longer serve as substitutes, but as complements. It is considered to be an opportunity rather than a necessity. Psychological research has shown that in personal contacts, face-to-face visual clues, such as facial expression, gesture and posture, play a significant role in understanding and trusting the other party and can give all participants the impression that the others can be influenced more, thus making it appear more worthwhile to enter into cooperation (Putnam 1993; Misztal 2000). Misztal (2000) proved that informal meetings still matter, as face-to-face contacts have the potential to draw individuals deeper into relationships with one another and to develop trust and intimacy. MaCAUlay (1963) observed that business people trust in and rely on a person's word in a brief letter or a handshake, even if they take greater risks concerning the transaction. Moreover, experiments revealed that in face-to-face discussion, participants reach agreement sooner than in any other negotiation setting. This leads to greater confidence in the negotiation processes. Informal interaction contributes to greater flexibility. Firms have more freedom to adjust to specific circumstances. For example, firms can respond quickly without taking into account and discussing fixed contractual arrangements first. Additionally, studies discovered that personal contacts make negotiations more an issue between two people than one between two firms, and negotiations are less formalised.

Researchers such as DUYSTERS et al. (1999), and recently PIDDUCK $(2006,265)$, argue that "a new perspective on partnership is needed to handle recent rapid economic and technological developments, and propose a more personal approach to partnership". GRANOVETTER (1985) is thought to be the first to have intensively studied the effect of social networks on business success. Social networks transform into business networks and determine the choice of economic trading partners and how to interact with them. Empirical information on social networks proved the positive effects on economic development and democracy (PUTNAM 1993; PUTNAM 2000), economic exchange (COlEMAN 1990; BURT 1992), education (COLEMAN 1988) and career success (BAKER 2000). The advantages of informality have been recognised by firms. Therefore, some elements, for example face-to-face negotiation, are part of general business practices, rather than merely a specific phenomenon observed in China or HK, which may only occur there more frequently. Social networks are particularly beneficial when economic transactions take place in an environment of high risk and uncertainty. In the case of China, it must be in- 
vestigated as to whether guanxi, originating as a social network, can transform into a comprehensive business network while preserving its efficient informal elements.

\section{Geography matters - regional institutions} in the study region Greater Pearl River Delta Recently, the academic discussion in economic geography has stressed the spatial scale of institutions by applying concepts from the New Institutional Economics to an institutional economic geography (GERTLER 2010; BOSCHMA/ FRENKEN 2009; BosCHMA/FRENKEN 2006). Economic interaction is shaped by a set of rules that are actively produced and reproduced over time and are typically bound to a particular region (GERTLER 2010). Some regions provide comprehensive formal rules and laws to protect economic transactions, while others provide socially derived, well accepted informal rules of doing business. The dependency of firms' behaviour on the regionally specific institutional environment may be studied by examining cross border business operations between regions with two different institutional settings. The Greater Perl River Delta (GPRD) serves as a perfect study region for this phenomenon. The GPRD consists, on the one hand, of HK, a former British colony with a formal institutional environment corresponding to the international standard. On the other hand, there is the PRD, a transitional economy. Although firms in HK and the PRD act in distinct formal institutional settings, they have the same social roots resulting in similar informal institutions across the border. Production is usually organised in the PRD, whereas firms in HK serve as intermediaries for exporting and importing products to and from industrialised countries. HK firms are somewhat janus-faced (MEYER et al. 2009). One face is turned to the PRD producers, the other face is turned to the world's leading firms as customers of products made in China.

The unique institutional environment in the GPRD lends itself to the empirical testing of three hypotheses:

(1) Firms in HK, working in two distinct institutional settings, organise business operations differently when dealing with PRD producers and global customers. According to this hypothesis, HK firms should work on a more informal basis with PRD producers due to the underdevelopment of comprehensive formal institutions in China, but on a more formal basis with global customers. The persistently unsatisfactory enforcement of formal laws combined with the lack of interwovenness of formal and informal institutions in the PRD lead to the expectation that Chinese firms do not yet rely on formal safeguards to ensure transactional success. FEARON/LAitin (1996, 730) found that social networks are better developed and interactions are more frequent within ethnic groups because they share certain similarities. Since entrepreneurs in HK and the PRD have the same ethnic and therefore social roots, their way of doing business on an informal basis is easier to realise, as it is driven by the concept of guanxi. The degree of informality in interactions is expected to be higher in HK firms' relations to PRD firms than to global customers.

(2) Since the rules of law in China have improved recently, the organisational behaviour has formalised to a certain extent, but informal organisation still prevails. According to the second hypothesis, interactions of HK firms with local producers are not completely informalised either. With the improvement of the institutional setting in China, HK entrepreneurs have formalised their relations with PRD producers to a certain extent. But since they know about the advantage of informal interactions (e.g. reciprocity, mutual understanding, flexibility), they may consider a combination of formal and informal interactions to be most beneficial for their relations with producers. This would provide evidence for the importance of personal interactions even going beyond the institutional setting. In the empirical section, the intensification of formal vs. informal interactions will be studied, comparing the behaviour of HK entrepreneurs when working with PRD producers and Western customers.

(3) Informal methods enable HK firms to engage in more flexible behaviour and respond quickly to market and customer requirements. Informality as an opportunity implies that firms benefit from informal behaviour. One expected benefit is more flexible behaviour leading to quick reaction opportunities, for example. Trust-based relations could relax negotiation processes, 
ease the changing of agreements or encourage the enforcement of agreements through social power.

\section{Operationalisation of informal interactions in business}

Li (2007) discussed the contrasting terms of formality and informality of firms' behaviour. He distinguished between formal and informal attributes of interaction, whereby these mark the extreme points of a continuum. According to $\operatorname{LI}(2007,229)$, informality in interactions on the micro-level "refers to the nature of social ties and events as implicitly assumed, endogenously embraced and flexibly enforced by horizontal ... pressures in a particularistic personalized process ..., while formality as explicitly prescribed, exogenously imposed and rigidly enforced by vertical authority powers in a ... depersonalized process." To study formal and informal behaviour, he proposed dimensions of informality as a framework to study and measure empirically formal and informal practices in business interactions. He recommended taking into account the degree of personalisation in business interactions, the form of agreements concluded, the precision of arrangements, the enforcement mechanisms of contracts and the power of institutions used (Tab. 2).

LI (2007) divided each dimension into a variety of actions ranging from formal to informal. Taking the first dimension, personalisation, into account, he refers to business contacts that can be highly impersonal (formal) or very personal (informal). Personal processes are based on face-to-face contacts, trust between partners and private involvement. This may also determine the second dimension, the form of agreements. Contracts can be highly formalised in a written way or informally agreed on in a verbal way, when partners trust each other's word. Not only the form of agreements, but also the precision of agreements (third dimension) can range from very precise (formal) to openended (informal). Business culture can rely on open-ended agreements with permanent renegotiations rather than specifying details in advance. Formal and informal agreements rely on different enforcement mechanisms, which can either be very tight at the one extreme or very loose at the other. In the case of conflicts, the power used to enforce agreements can be legal via courts or social power relying on shared norms within a culture (Li 2007; SINDZINGRE 2006). A firm may be characterised as acting on informal constraints in terms of customerproducer relations when dimensions tend to be specified by informal practices. In contrast, a firm is characterised as acting on formal constraints in terms of customer-producer relations when dimensions tend to have a formal shape.

Here a special focus is placed on these three dimensions, namely personalisation in business interactions, the form of agreements concluded and the precision of arrangements. Along these dimensions, it will be tested empirically as to how high the degree of informality applied in business interactions is, comparing firms acting in two different institutional settings. To test the dimension of personalisation, the instruments of HK entrepreneurs for contacting and selecting customers and producers were studied. Contacting and selecting processes can be based on personal or impersonal ties, which refer to informal or formal modes re-

Tab. 2: Formal-informal dimensions in business interactions

\begin{tabular}{|c|c|c|c|}
\hline Dimensions & Formal & Informal & Operationlisation \\
\hline Personalisation & impersonal & personal & $\begin{array}{l}\text { Contacting and selecting of customers } \\
\text { and producers }\end{array}$ \\
\hline Form of agreements & written & verbal & Form of manufacturing agreements \\
\hline Preciseness of agreements & precise & open-ended & $\begin{array}{l}\text { Details fixed in manufacturing agree } \\
\text { ments }\end{array}$ \\
\hline Enforcement of agreements & tight & \multirow{2}{*}{\multicolumn{2}{|c|}{$\begin{array}{l}\text { loose } \\
\text { social (horizontal) }\end{array}$}} \\
\hline Power & legal (vertical) & & \\
\hline
\end{tabular}

Source: own composition according to Li 2007, 229ff.) 
spectively. There are two arguments as to why informal means might be used in contacting and selecting processes:

- In the neoclassical theory, firms are expected to contact and select their business partners by evaluating their rational factors of success (e.g. for example firm performance, product quality) (ANGELES/NATH 2000; HitT et al. 2000; SAFfu/MAMman 2000). This could be interpreted as an impersonal and therefore formal method of contacting customers and producers. But bounded rationality limits the scope of firms for assessing a potential partner's quality and reliability in advance. Even though firms can assess potential partners' quality and reliability within a screening scheme of their own (formal), they can trust in a network of firms with pooled experiences (informal). Empirically, Menard (2004, 361) could prove that the use of informal modes through networking to gain new customers and producers opens up additional opportunities for firms without weakening any formal modes.

- Under volatile industry and market conditions with changing demand, time is essential for a firm's competitiveness. As a personal network is always ready to use, it seems to be a quicker way of activating new customers and producers at short notice (Millington et al. 2006).

In order to study the dimensions of precision and form of contracts, HK firms' contracts with customers and producers pertaining to the manufacturing of electronics products were investigated. Emphasis was placed on the details fixed and the form of contracts. Again, there are three arguments as to why informal means might be used.

- When the formal institutional environment does not provide safeguards for the enforcement of contracts, the incentive of firms to design precisely written contracts is low. Firms have to protect their transactional interests in other ways. A trust-based relationship, as which guanxi may be characterised, in which parties rely on reputation and reciprocity, provides informal safeguards which lead to self-enforcing contracts (POWELL 1990; Dimaggio/Louch 1998; Menard 2004, 362). Despite improvements in the PRD, the institutional framework does not provide firms with the appropriate safeguards for protecting their transactions efficiently. Even if contractual details are formally fixed and verifiable, it is still difficult to enforce them through courts (MENARD 2004, 360).

- Informal modes in contracting can also be expected due to the low impact of contracts in Chinese business culture. Contracts are not the results of intensive negotiations, but are seen rather as the beginning of a relationship over a much longer time period (see guanxi). Therefore, the permanent renegotiation of contracts is a process which accompanies the development of the relationship.

- There is, however, another argument: Firms still weigh the costs of anticipating, devising optimal responses to and drafting provisions for future events against the value which would be lost in the case of conflicts. Only when transaction-specific investments are high is it worth incurring the considerable costs of administering complex and highly detailed contractual arrangements (model in HART/Moore 2004, 5 ff.; MASten 2000). Under certain circumstances, firms are expected to attempt to agree only on the most necessary details (SEGAL 1999, 74). Besides cost motives, this is associated with greater flexibility. Firms can speed up the contractual process and revise and renegotiate on a steady platform in order to adapt to changing demand. In industries with rapidly shifting technologies and markets, firms need adjustable contracts embedded in networks to ensure the ability to react to the changing demand profiles of end customers (ERNST 2004, 106).

Despite the positive effects of informality on business interactions, one has to consider that it takes a lot of time and effort to build social ties. HUMPHREY/ASHFORTH (2000) showed that interpersonal relationships can also lead customers to award contracts to producers who have higher unit costs, lower quality and slower delivery times. Nevertheless, networks may also lead to a lock-in, if firms rely on them exclusively. Therefore, they need to be supported by formal structures to guard against the negative effects of informality, such as opportunistic behaviour and its intransparency (MISZTAL 2000, 7). 


\section{Data and methods}

Informality will be studied empirically, involving a comparison between the organisation of customer and producer relations of HK firms. Emphasis is placed on the contacting and selecting procedures and the contractual arrangements. To avoid sector-related skewness, the study was concentrated on one industry. The electronics industry in the GPRD was selected because of its large contribution to the economic growth in the GPRD and its dynamics (CANFEI et al. 2008). The electronics industry in the PRD is responsible for $38 \%$ of all Chinese electronics exports and $32 \%$ of the gross industrial output. $47 \%$ of foreign direct investments come from HK (Guangdong Provincial Bureau of Statistics 2006).

As there is a shortage of secondary data on this issue, a firm survey was conducted in HK focussing on the electronics industry. On a micro-level, a survey of small and mediumsized electronic firms was conducted in $\mathrm{HK}$ in 2007 and 2008 to collect information on how HK firms organise relations to their PRD producers as well as to their global customer base. This was intended to show whether informal interactions are only applied in relations to PRD firms as a necessity for manoeuvring around institutional incompleteness, or whether HK firms also see advantages in organising business with customers in an informal way.

The survey was based on the firm directory of the Hong Kong Trade Development Council. From 4,903 registered small and medium-sized HK electronic firms, a random sample of 2,000 was selected. In a stepwise process, 1,000 firms were chosen first, followed by another sample of 1,000 firms due to the low return rate from the first sample. The survey concentrated on firms with not more than 100 employees in $\mathrm{HK}$ according to HK statistical standards. Although a standardised survey was conducted, the information was collected personally in an hour-long interview to ensure high quality. CEOs or senior managers of 104 firms agreed to an interview (5\% return rate). Although the Social Science Research Center of the Hong Kong University (SSRC), who provided strong support in contacting and interviewing firms, is very professional and experienced, gaining $\mathrm{HK}$ CEOs for an interview proved to be very difficult. The low response rate may be explained by the fact that people in these positions were requested to participate due to the strategic ori- entation of the survey. Unfortunately, potential respondents often spend most of their time in their Chinese factory and were hardly available in HK. Moreover, we wanted CEOs to be interviewed personally in order to ensure the quality of the survey results, rather than using self-completed questionnaires, which also dropped the return rate. Additionally, HK firms are the target group of many surveys. As we cooperated with SSRC, we already had a strong academic partner for the interviews, which led to a reasonable response rate for HK circumstances, but in comparison to other surveys, the response rate is lower. However, since the collection of empirical data on informality in interactions is still at an explorative stage, no attempt was made to produce representative results. The accessibility of firms and reliability of data was of primary importance. Nevertheless, it could be proven that there is no significant difference between sample and population according to employment size.

\section{Applying informal interactions: contacting, selecting and contracting}

The previous sections raised the question of whether the institutional environment requires informal actions as a necessity or whether informal interactions could also be seen as an opportunity for firms. This section empirically studies the degree of informality applied in the customer-producer relations of HK firms in terms of contacting and selecting procedures and contractual arrangements, depending on the institutional environment.

\section{Contacting and selecting of customers and producers}

Contacting: When firms wish to contact new customers and producers, they may choose from a variety of methods ranging from very impersonal to very personal. The importance of seven different contact channels of HK firms for gaining new global customers (non-Chinese) is shown in Tab. 3. In the second part, the selecting processes of PRD producers will be studied as a comparison. Contact channels range from being very personal, and therefore informal (private contacts), to very impersonal, and therefore formal (bidding competition). HK firms were asked to assess their importance on a Likert scale $(1=$ very important to 5 $=$ not important). Recommendations by business partners are, as is shown in Tab. 3 , the 
most important (61\%). This requires a network of trustworthy business partners to receive recommendations. Whereas business contacts seem to be of importance, private networks are not $(8 \%)$. Sales agents are the second most important $(54 \%)$. Sales agents are responsible for contacting and keeping in touch with customers. The personal contact is important, as this creates an atmosphere of trust. However, sales agents account for moderate informality. In contrast, gaining customers at exhibitions is less personal, while gaining them on the internet or through bidding competitions is even more impersonal, and therefore very formal. Exhibitions and internet contact is third in terms of importance. Formal bidding processes, the contacting of former customers and private contacts are of minor importance. The $\mathrm{Chi}^{2}$-test shows that the indicated shares significantly differ from an equal distribution.

Contacting channels with a medium degree of informality scored highest when HK firms contact global customers, although the institutional environment would allow them to rely on formal means only. Apparently, a certain degree of informality is conducive to business success. When firms can revert to networks, they enlarge their pool of choices for contacting and selecting partners. Very impersonal contact channels are at everybody's disposal, but personal channels are not available to all firms.

Although formal safeguards can be ensured by a functional legal system in HK and transac- tions with strangers can be ensured by contracts, recruitment within networks might still be appealing because of cost-reducing and time-saving aspects. Even if HK firms contact global customers, they prefer the use of networks and other moderately informal means. This raises the question of how guanxi networks are affected by institutional change. Xin/Pearce (1996) and NeE (1992) see guanxi as a substitute for the deficiencies of formal institutional artifacts and failures in the legal system. Proponents of this thesis argue that guanxi will become less important in the future. On the other hand, other experts argue that guanxi is also transforming into a more functional business network. Whereas the traditional guanxi network consists of family (zijiaren) and fellows/helpers (shouren), it has now changed to strangers/business partners (shengren), which makes it more effective for business (MilLINGTON et al. 2006). Studies of business culture in HK or Taiwan are widely used to provide examples of the transition - but nevertheless survival - of guanxi in the modern market (FAN 2002; ZHANG/ZHANG 2006).

The importance of business networks in comparison to private networks confirms the change of the nature of guanxi from a private to a functional network. This functional guanxi network is driven by personal connections. When firms in HK use their guanxi networks, they profit from the intangible, transferable and reciprocal character of the network. Other network members are committed either to provid-

Tab. 3: Importance of formal and informal contacting channels of HK firms to global customers (in \%)

customers abroad $(\mathrm{n}=93)$

important $\begin{aligned} & \text { moderate not } \\ & \text { important important }\end{aligned} \mathrm{Chi}^{2} \quad$ significance

\begin{tabular}{|c|c|c|c|c|c|}
\hline (1) Bidding competition & 19 & 9 & 72 & 64.323 & .000 \\
\hline (2) Internet & 48 & 27 & 25 & 9.548 & .008 \\
\hline (3) Exhibitions and fairs & 51 & 26 & 24 & 12.452 & .002 \\
\hline (4) Sales agents & 54 & 22 & 25 & 17.613 & .000 \\
\hline $\begin{array}{l}\text { (5) Recommendation by } \\
\text { business partners }\end{array}$ & 61 & 26 & 13 & 35.032 & .000 \\
\hline $\begin{array}{l}\text { (6) Former business } \\
\text { relationship }\end{array}$ & 22 & 14 & 65 & 41.484 & .000 \\
\hline $\begin{array}{l}\text { (7) Private contacts } \\
\text { (e.g. family ties) }\end{array}$ & 8 & 12 & 81 & 93.935 & .000 \\
\hline
\end{tabular}

Note: Importance is measured on a Likert scale with $1=$ very important to $5=$ not important, mean value indicated. Source: calculation based on own survey conducted in DFG SPP 1233 [2007] 
ing their services to the firm (intangible), or they recommend a third party (transferable) (Dimaggio/Louch 1998). Firms save ex ante transaction costs for screening their environment for new customers and producers, collecting information and establishing the first contact, but they also hope to achieve better safeguards than in a formal process (PowELL 1990; DimagGio/Louch 1998; GranOVETTER 1985). Former experiences may be used as an indicator for future satisfaction (MACLEOD 2006). If a producer has acquired a good reputation in a business network, it is treated as an asset which loses its value should the producer disappoint customers (MACLEOD 2006; ARAUJO/ORNELAS 2007:3). As networks are recipro$\mathrm{cal}$, firms are willing to repay favours. Preliminary empirical evidence was found in the study of GASTON/Bell (1988). They proved that two-thirds of investors in the informal capital market find investments through their networks. The most reliable sources are friends and business partners. SHILler/Pound (1989) confirmed those findings. They found that the majority of purchasers of publicly traded common stocks buy based on information from friends and business associates. Networks are usually developed on an individual level, but are often transferred to a firm level. This does not skew empirical findings as long as firms are small and/or family-led. The owner and manager is the same person and the owner's network is identical to the firm's network. This mainly applies to small and medium enterprises (SME) in HK. In large firms with frequent changes in management positions, a distinction must be made between the networks of individuals and those of the firm.

In conclusion, $\mathrm{HK}$ firms proved that contacting channels have not yet formalised completely, and that informal modes retain their importance. This is also in accordance with the theory outlined by ZENGER et al. (2002). Formal institutions do not necessarily go along with formal interactions, but provide room for the use of informal as well as formal actions.

Selecting: It is expected that the contacting of customers and producers is carried out on a continual basis. A selection occurs if a new partner is needed. Selection processes are of

Tab. 4: Importance of formal and informal selection criteria of HK firms for producers in equity cooperation and non-equity cooperation (in \%)

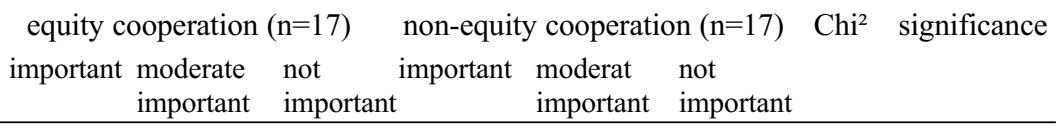

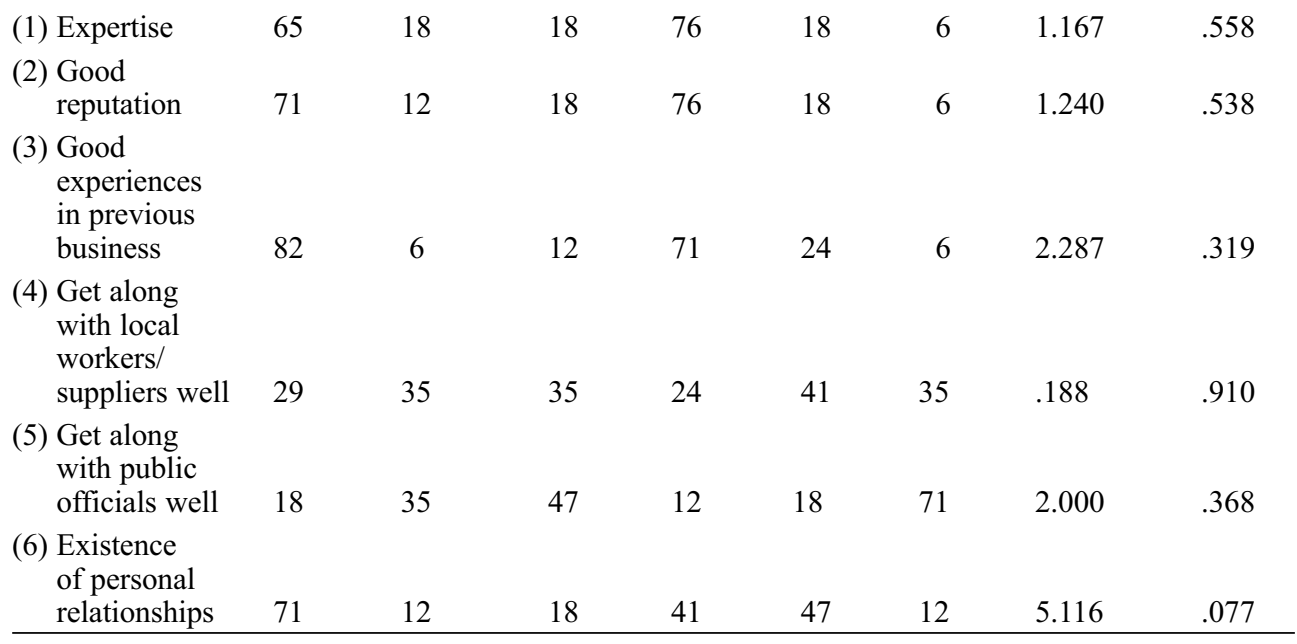

Note: Importance is measured on a Likert scale with $1=$ very important to $5=$ not important, mean value indicated. Source: calculation based on own survey conducted in DFG SPP 1233 [2007] 
particular interest when firms look for new cooperation partners. MEYER et al. (2009) outlined that cooperation with PRD producers has become more important for HK firms in recent years. Therefore, the selection criteria for PRD producers in cooperation were analysed using the dimension 'personalisation' in the informality pattern. Selection criteria can range from very formal, without any involvement of personal assets, to very informal, which qualifies producers only because of personal relations. Expertise can be seen as an objective measurement of skills and is therefore very impersonal. A good reputation is based on a pool of subjective measurements and is therefore deemed to be impersonal, but not as impersonal as expertise. Positive experiences in previous business dealings are based on a firm's own subjective measurement of the producer's quality. It is linked to moderate personalisation. In contrast, selection criteria are more personal when they qualify producers to get along well with local workers, suppliers and public officials. When a producer is qualified because of a private connection, this counts as informal.

For analysis, the focus is on cooperative relations, as they are concerned with the highest degree of mutual interaction and potentially informal traits. For simple reasons, there is a distinction between equity cooperation and nonequity cooperation of HK firms with PRD producers. Equity cooperation with Chinese firms was mandatory at the beginning of the transformation process and could be considered as the oldest mode of cooperation existing between HK firms and Chinese producers. Nonequity cooperation was a free-choice decision that appeared with the modernisation of Chinese laws. The differentiation between equity cooperation (e.g. joint ventures) and non-equity cooperation (e.g. loosely concluded cooperation agreements) provides interesting results about firms' preferences within those relationships and potential changes in cooperation. It can be seen, for example, whether personal relations still steer cooperation or whether they are equally important to other formal procedures.

When looking at equity cooperation, Tab. 4 shows that positive experience in previous business dealings is of the greatest importance $(82 \%)$, followed by a good reputation of producers and the existence of personal relationships (both $71 \%$ ). HK firms' selection criteria for producers in equity cooperation are based on subjective quality measurements and personal relationships. Informal and moderately informal criteria are mainly applied. However, when turning to non-equity cooperation, expertise as an objective means of measuring the quality of producers is of the greatest importance, along with a good reputation (both $76 \%$ ). The third most important factor is positive experience in previous business dealings $(71 \%)$. While some firms apparently need to smooth relationships to potential joint venture partners through informal modes, other firms working in non-equity cooperation set their priority on measurements of quality, for example personal relationships are much more important in equity than in non-equity relations. This also became significant in the $\mathrm{Chi}^{2}$-test.

The findings showed that a successful partnership in non-equity cooperation is characterised by expertise and a good reputation of producers in combination with mutual understanding. In contrast, equity cooperation follows another strategy. It is mainly applied to running the business. This was the way in which HK firms were forced to work at the beginning of the Chinese opening policy. The way equity cooperation is seen by HK firms does not seem to have changed over recent years. There is an initial signal for a difference in importance of personal relations, and Guanxi might change from a purely personal to a business network. Moreover, it can be observed that in a modern non-equity relationship, HK firms balance for$\mathrm{mal}$ and informal criteria instead of purely relying on informal ties. But to a certain extent, informality remains an opportunity. As these findings are only a preliminary sign, this issue definitely requires further research.

In summary, the findings on contacting and selecting procedures of $\mathrm{HK}$ firms show, first, that personal relations are much more important when dealing with firms in China than with global customers, which is an expression of the influence of the institutional setting. But second, it could be shown that HK firms still use informal modes to contact and select global customers, even though the institutional environment would allow a reliance on formal modes only. This confirms again that a certain degree of informalisation smoothes business relations. HK firms tend to combine formal and informal modes in order to succeed. Formal and informal modes are not mutually exclu- 
sive, but rather complement each other. MiLLINGTON et al. (2006) also worked on the identification process of Chinese partners. Their findings also show that personal connections, and in particular guanxi, helped UK and US-invested manufacturers in China to select producers. They also observed, however, that guanxi nowadays consists of business rather than family and community connections.

\section{Contractual arrangements with customers and producers}

Precision and form of contracts: Once firms have contacted and selected their potential customers and producers, they have to settle transaction-specific details. This section provides evidence on how contractual arrangements are concluded. Two dimensions of informality are analysed: the form of agreements (written to verbal) and precision (precise to open-ended). Interviews with lawyers in the GPRD indicated that the following points require attention when contracts are concluded: product specification, quantity, price, delivery time, agreement on exclusivity, penalties for breach of contract.

The proportions of HK firms which fix all points in contracts are shown in Tab. 5 (see columns 'precision of contracts'). If points are fixed in contract, this could be in written form, verbal form or both (see columns 'form of contracts'). The more open-ended an agreement is and the more details are agreed on verbally, the greater the informal character of a contractual arrangement is. Again, a comparison is made between HK firms' contractual organisation to global customers and to producers in the PRD.

When looking at the precision as a dimension of informality, the findings show that more than three quarters of the necessary details are fixed before the actual production process starts. Only a small proportion of firms have imprecise and therefore informal contracts. A look at how points are fixed, the form of agreements, indicates that HK firms mainly keep to formal modes, although there is a slight trend towards more informal agreements with PRD producers. If points are agreed on in advance, the majority of HK firms fix important points in written form. In customer relations, an average of $51 \%$ of $\mathrm{HK}$ firms reported fixing all points in writing, while in producer relations, the figure was $46 \%$. An exclusively verbal agreement is only concluded by a very small number of firms (customers: $7 \%$, producers: $5 \%$ ). In producer relations, the combination of both written and verbal agreements is preferred by about one quarter of the firms, while in customer relations, the number drops to $20 \%$. Comparing customer and producer relations, it becomes clear that the number of written details in contracts is slightly higher with customers than with producers.

HK firms apply informal modes when contacting and selecting customers and producers, but when it comes to contractual arrangements, they mostly do not rely on trust and a hand

Tab. 5: Preciseness and form of framework agreements of HK firms

\begin{tabular}{|c|c|c|c|c|c|c|c|c|c|c|c|c|}
\hline \multirow[b]{3}{*}{ Product snecification } & \multicolumn{6}{|c|}{$\begin{array}{l}\text { Customers }(n=27) \\
\text { Precision of contracts }\end{array}$} & \multicolumn{6}{|c|}{$\begin{array}{c}\text { Producers }(n=38) \\
\text { Precision of contracts }\end{array}$} \\
\hline & sum & not fixed & fixed $^{a}$ & \multicolumn{3}{|c|}{$\begin{array}{l}\text { Form of contracts } \\
\text { written/verbal/both }\end{array}$} & sum & \multicolumn{2}{|c|}{ not fixed fixeda } & \multicolumn{3}{|c|}{$\begin{array}{c}\text { Form of contracts } \\
\text { written/verbal/both }\end{array}$} \\
\hline & 100 & 7 & $93 \rightarrow$ & 63 & 7 & 22 & 100 & 16 & $84 \rightarrow$ & 50 & 3 & 32 \\
\hline Quantity of products & 100 & 22 & $78 \rightarrow$ & 48 & 7 & 22 & 100 & 13 & $87 \rightarrow$ & 55 & 0 & 32 \\
\hline Price of products & 100 & 15 & $85 \rightarrow$ & 63 & 4 & 19 & 100 & 16 & $84 \rightarrow$ & 53 & 3 & 29 \\
\hline Delivery time & 100 & 15 & $85 \rightarrow$ & 59 & 7 & 19 & 100 & 13 & $87 \rightarrow$ & 58 & 5 & 24 \\
\hline $\begin{array}{l}\text { Agreement on } \\
\text { exclusivity }\end{array}$ & 100 & 37 & $63 \rightarrow$ & 33 & 7 & 22 & 100 & 47 & $53 \rightarrow$ & 32 & 5 & 16 \\
\hline $\begin{array}{l}\text { Penalties for } \\
\text { breach of contracts }\end{array}$ & 100 & 33 & $67 \rightarrow$ & 41 & 7 & 19 & 100 & 42 & $58 \rightarrow$ & 26 & 16 & 16 \\
\hline Mean & 100 & 22 & $78 \rightarrow$ & 51 & 7 & 20 & 100 & 25 & $75 \rightarrow$ & 46 & 5 & 25 \\
\hline
\end{tabular}

a sum of shares written, verbal and both

Source: calculation based on own survey conducted in DFG SPP 1233 [2007] 
shake, but prefer written agreements. When disputes occur, a written document is of higher value than a person's word. What could not be proven in the quantitative data, but has been derived from the interviews, is that although points are fixed in a written form, those written contracts are not comparable to what Westerners intuitively associate with written contracts. Family ties and long-term business relationships are reasons for non-dedicated contracts. Lawyers have often experienced that Chinese firms have only rudimentary contracts, even for large projects. Often, a one-page contract is concluded covering the main points, but it is not proofed by lawyers. Those contracts are very difficult to enforce by law in the case of disputes. LEE $(1997,189)$ shows that one third of HK managers rely on verbal contracts.

Informal contracts indicate greater flexibility: An important contribution of this work is to study the correlation of informality and flexibility. Although HK firms indeed indicated having formal contracts, there is some evidence for informal contracting as well. Initial proof of whether informal contracts lead to quicker response and greater flexibility can be considered as an answer to the question of whether informality serves as necessity or opportunity. It must be investigated as to whether informal contracts are perhaps of even greater advantage than formal contracts with respect to the time of negotiation. In order to prove the correlation of informality and flexibility, evidence must be found of informal contracts leaving more leeway for firms to arrange the actual order, saving them extra time and reducing transaction costs. Flexibility in contractual arrangements was measured according to the time in days required by firms to negotiate details before the production process could start. What effect informal contracts have on the time between the beginning of negotiations and the start of production in contrast to formal contracts is shown in Tab. 6, distinguishing between customers and producers. HK firms which have informal contracts with their pro- ducers indicated a shorter negotiation time on average than firms with formal contracts (three days instead of five days). In this case, informal contracts seem to allow more leeway for final negotiation, which reduces negotiation time before production can start. In a rapidly changing business environment, the costs of drawing up a comprehensive contract are extremely high. PRD firms in particular, as component suppliers of HK firms, suffer from permanently changing market conditions and poor forecasting systems, which increases their need for flexibility. When producers are located within the PRD, informality in contractual arrangements works well in combination with spatial proximity and guanxi, as information may be verbally agreed on and revised. This finding cannot yet be generalised due to the low number of cases. Moreover, the difference between three and five days is not significant. This finding only serves as an initial signal for the advantages of informal behaviour, but definitely needs further investigation.

Informal agreements with customers reduce the time required for negotiation when an actual order is placed from seven days to six days. It seems to be more difficult to agree upon actual orders when the contract is informally organised in long-distance customer relationships, because the absolute negotiation time is longer. Again, due to the low number of cases, the findings cannot be generalised. Potential explanations for this observation could be that forecasting systems of $\mathrm{HK}$ firms are better and the need for flexibility is lower, therefore informal agreements are of advantage, but formal agreements can hold their own in terms of speed. As HK firms and international customers work in a complete institutional environment, transaction costs for concluding written contracts are lower. Additionally, this seems to be of advantage for the enforcement of contracts, as the legal system provides firms with sufficient enforcement mechanisms. LYONS (1994) investigated firms in France and found that contracts between firms usually tend

Tab. 6: Effects of formal and informal framework agreements on the negotiation time

\begin{tabular}{lllll} 
& \multicolumn{2}{l}{ Customers } & Producers & \\
& $\mathrm{n}$ & Time of negotiation & $\mathrm{n}$ & Time of negotiation \\
\hline Formal Contract & 18 & 7 days & 23 & 5 days \\
Informal Contract & 9 & 6 days & 15 & 3 days \\
\hline
\end{tabular}

Source: calculation based on own survey conducted in DFG SPP 1233 [2007] 
to be informalised when they work in rapidly changing business environments, because the costs of drawing up a comprehensive contract are too high.

\section{Conclusion}

The aim of this paper was to show the underestimated importance of informal interactions for business operations in transitional economies, which serve more purposes than simply to replace dysfunctional formal rules. The GPRD, with its distinct institutional setting, served as an example to prove to what extent informality serves as an opportunity or as a necessity. Informal ties in firm networks are maintained to some extent due to their high efficiency, even if formal institutions are developed to international standards. Informal interactions turned out not only to be considered as a substitute for missing formal rules, but as a complement. A firm survey in HK in 2008 delivered the empirical data to prove the hypotheses. 104 small and medium-sized firms were interviewed. As the quality of the survey was of great importance, the return rate was only $5 \%$. This also resulted in a low number of cases for analysing specific questions. As this study is of an explorative nature, representative results were not aimed for. The findings cannot be generalised, but they deliver initial signals for a positive assessment of informality, which should be considered for further research.

It could be proven that HK firms apply a lower degree of informalisation in relations with global customers than with local producers when contacting and selecting partners as well as designing contracts (hypothesis 1). However, when firms work with producers in the PRD, they do not rely purely on informal ties, but have a healthy balance of formal and informal behaviour (hypothesis 2). For contacting and selecting partners, firms use their networks instead of the formal procedure of quality assessment. Contracts are mainly fixed in writing, but they only cover the most important details, which are subject to negotiation afterwards. It turned out that HK firms use informal ties to organise business with global customers as well. They do not only use informality as a necessity in dealing with Chinese firms, but also see it as an opportunity to increase their variety of modes to do business. Therefore, it can be expected that the world's factory for electronic products in the GPRD will continue to rely on informal ties between firms, even if China makes an effort to improve its formal institutional environment. In order to prove this, further research is needed to see whether informal ties in reality overcome the discussion about the influence of institutions on firms' behaviour, and to what extent. There were also empirical signals confirming hypothesis 3 . The data showed that informal contracting reduces the time of negotiating contracts and therefore increases flexibility. This is initial proof for informality providing an opportunity for firms. Informality is not limited to necessity. As the number of cases is low, further investigation is required here.

Without being a newly introduced business concept to firms in the GPRD, the strategic application of informal interaction may be an innovative approach to Western firms. With this study having stepped forward in identifying the relevance of informal interactions, a sound empirical analysis is desirable in order to clarify the patterns and mechanisms in more detail.

\section{Acknowledgement}

I would like to thank my colleague Daniel Schiller for the fruitful discussions and joint development of the idea to study informality from the perspective of necessity and opportunity. This paper is the result of our idea. Moreover, I would like to thank the anonymous reviewer for her/his helpful comments on earlier versions of the paper. Funding for this research was received from the German Research Foundation (DFG) within the Priority Programme (SPP 1233) "Megacities-Megachallenge - the informal dynamics of global change" under grant RE 1720/8-1.

\section{References}

Angeles, R./NAth, R. (2000): An empirical study of EDI trading partner selection criteria in customer-supplier relationships. In: Information \& Management, (37)5, 241-255.

Araujo, L./Ornelas, E. (2007): Trust-based trade. London. (CEP Discussion Paper No 820, Centre for Economic Performance, London School of Economics and Political Science).

BAKER, W. E. (2000): Achieving success through social capital. Tapping the hidden resources in your personal and business networks. San Francisco.

Boschma, R./Frenken K. (2009): Some notes on institutions in evolutionary economic geography. In: Economic Geography, (82)5, 151-158. 
Boschma, R./Frenken K. (2006): Why is economic geography not an evolutionary science? Towards an evolutionary economic geography. In: Journal of Economic Geography, 6, 273-302.

BuRT, R. S. (1992): Structural holes: the social structure of competition. Cambridge.

CANFeI, H./WeI, Y.D./ XiuZhen, X. (2008): Globalization, institutional change, and industrial location. Economic transition and industrial concentration in China. In: Regional Studies, (42)7, 923-945.

Coleman, J.S. (1988): Social capital in the creation of human-capital. In: American Journal of Sociology, 94, 95-120.

Coleman, J.S. (1990): The foundations of social theory. Cambridge.

Dimaggio, P./Louch, H. (1998): Socially embedded consumer transactions. For what kinds of purchases do people most often use networks? In: American Sociological Review, (63)5, 619-637.

DunNIng, J. H./KIM, C. (2007): The cultural roots of Guanxi. An exploratory study. In: World Economy, (30)2, 329-341.

Duysters, G./KoK, G./VAandrager, M. (1999): Crafting successful strategic technology partnerships. In: R\&D Management, (29)4, 343-351.

ERNST, D. (2004): Global production networks in East Asia's electronics industry and upgrading prospects in Malaysia. In: Yusuf, S./Altaf, M.A./Nabeshima, K. (Eds.): Global production networking and technological change in East Asia. Washington, 8-157.

Etzold, B./KecK, M./Bohle, H.-G./Zingel, W.-P. (2009): Informality as agency. Negotiating food security in Dhaka. In: Die Erde, (140)1, 1-22.

FAN, Y. (2002): Questioning guanxi. Definition, classification and implications. In: International Business Review, 11, 543-561.

FEARON, J.D./LAitin, D.D. (1996): Explaining interethnic cooperation. In: American Political Science Review, (90)4, 715-735.

GAston, R. J./BELL, S. (1988): The informal supply of capital. London. (Tech. report, Office of Economic Research, U.S. Small Business Administration).

GERTLER, M. (2010): Rules of the game: The place of institutions in regional economic change. In: Regional Studies, (44)1, 1-15.

Granovetter, M. (1973): Strength of weak ties. In: American Journal of Sociology, (78)6, 1360-1380.

Granovetter,, M. (1985): Economic-action and socialstructure. The problem of embeddedness. In: American Journal of Sociology, (91)3, 481-510.

Guangdong Provincial Bureau of Statistics (2006): Guangdong statistical yearbook 2006. (China Statistics Press).

Guangdong Provincial Bureau of Statistics (2007): Guangdong statistical yearbook 2007. (China Statistics Press).

Hart, O./Moore, J. (2004): Agreeing now to agree later. Contracts that rule out but do not rule. (China Statis- tics Press) (Harvard Law and Economics Discussion Paper No. 465; Harvard Institute of Econ. Research Disc. Paper 2032).

Hitt, M.A./Dacin, M.T./Levitas, E./Arregle, J.L./BorzA, A. (2000): Partner selection in emerging and developed market contexts. Resource-based and organizational learning perspectives. In: Academy of Management Journal, (43)3, 449-467.

Humphrey, R. H./AshForth, B.E. (2000): Buyer-supplier alliances in the automobile industry. How exitvoice strategies influence interpersonal relationships. In: Journal of Organizational Behavior, (21)6, 713-730.

LEE, M.-K. (1997): The flexibility of the Hong Kong manufacturing sector. In: China Information, (12)1/2, 189-214.

LI, P.P. (2007): Social tie, social capital, and social behaviour. Toward an integrative model of informal exchange. In: Asia Pacific Journal of Management, 24, 227-246.

Luo, Y./CHEN, M. (1997): Does guanxi influence firm performance. In: Asia Pacific Journal of Management, 14, 1-16.

LYONS, B.R. (1994): Contracts and specific investment. An empirical test of transaction cost theory. In: Journal of Economics and Management Strategy, (3)2, 257-278.

Macaulay, S. (1963): Non-contractual relations in business. A preliminary-study. In: American Sociological Review, (28)1, 55-67.

MACLEOD, W.B. (2006): Reputations, relationships and the enforcement of incomplete contracts. Ney York. (Center for Economic Studies \& Institute for Economic Research, Working Paper 1730).

Masten, E.S. (2000): Contractual choice. In: Boukaert, B./De Geest, G. (Eds.): Encyclopedia of Law and Economics. Cheltenham, 25-45.

MENARD, C. (2004): The economics of hybrid organizations. In: Journal of Institutional and Theoretical Economics, (160)3, 345-376.

Meyer, S./Schiller, D./Revilla Diez, J. (2009): The Janus-faced economy: Hong Kong firms as intermediaries between global customers and local producers in the electronics industry. In: Tijdschrift voor economische en sociale geografie, (100)2, 224-235.

Millington, A./Eberhardt, M./Wilkinson, B. (2006): Guanxi and supplier search mechanisms in China. In: Human Relations, (59)4, 505-531.

MiszTAL, B. (2000): Informality. Social theory and contemporary practice. London.

NeE, V. (1992): Organizational dynamics of market transition. Hybrid forms, property-rights, and mixed economy in China. In: Administrative Science Quarterly, (37)1, 1-27.

NORTH, D. (1990): Institutions, institutional change and economic performance. Cambridge.

PARK, S.H./LuO, Y.D. (2001): Guanxi and organizational dynamics. Organizational networking in Chinese firms. In: Strategic Management Journal, (22)5, 455477. 
PIDDUCK, A.B. (2006): Issues in supplier partner selection. In: Journal of Enterprise Information Management, (19)3, 262-276.

Powell, W.W. (1990): Neither market nor hierarchy. Network forms of organization. In: Research in Organizational Behavior, 12, 295-336.

PutnAm, R.D. (1993): Making democracy work. Civic traditions in modern Italy. Princeton.

Putnam, R.D. (2000): Bowling alone. The collapse and revival of American community. New York.

Richter, R./Furubotn, E. (1996): Neue Institutionenökonomik. Eine Einführung und kritische Würdigung. Tübingen

SAFFU, K./Mamman, A. (2000): Mechanics, problems and contributions of tertiary strategic alliances. The case of 22 Australian universities. In: Library Consortium Management: An International Journal, (2)2, 44-53.

Segal, I. (1999): Complexity and renegotiation. A foundation for incomplete contracts. In: Review of Economic Studies, (66)1, 57-82.

Shiller, R.J./Pound, J. (1989): Survey evidence on diffusion of interest and information among investors. In: Journal of Economic Behavior \& Organization, (1)1, 47-66.
SINDZINGRE, A. (2006): The relevance of the concepts of formality and informality. A theoretical appraisal. In: Guha-Khasnobis, B./Kanbur, R./Ostrom, E. (Eds.): Linking the formal and informal economy. Concepts and policies. Oxford, 58-74.

WiLliamson, O. (2000): The new institutional economics. Taking stock, looking ahead. In: Journal of Economic Literature, (38)3, 595-613.

Xin, K.R./Pearce, J.L. (1996): Guanxi: Connections as substitutes for formal institutional support. In: Academy of Management Journal, (39)6, 1641-1658.

Yeung, H.W. C., LiN, G.C.S. (2003) Theorizing economic geographies of Asia. In: Economic Geography, (79)2, 107-128.

Zenger, T.R./LAZZARINI, S.G./Poppo, L. (2002): Informal and formal organization in new institutional economics. In: New Institutionalism in Strategic Management, 19, 277-305.

ZHANG, Y./ZHANG, Z.G. (2006): Guanxi and organizational dynamics in China. A link between individual and organizational levels. In: Journal of Business Ethics, (67)4, 375-392. 